\title{
Co-targeting of DNA, RNA, and protein molecules provides optimal outcomes for treating osteosarcoma and pulmonary metastasis in spontaneous and experimental metastasis mouse models
}

\author{
Chao Jian',2, Mei-Juan Tu², Pui Yan Ho², Zhijian Duan², Qianyu Zhang ${ }^{2}$, Jing-Xin \\ Qiu $^{3}$, Ralph W. DeVere White ${ }^{4}$, Theodore Wunn ${ }^{5}$, Primo N. Lara ${ }^{5,6}$, Kit S. Lam², Ai-Xi \\ $\mathbf{Y u}{ }^{1}$ and $A i-M i n g ~ Y u^{2}$ \\ ${ }^{1}$ Department of Orthopedics, Zhongnan Hospital of Wuhan University, Wuhan, Hubei, China \\ 2 Department of Biochemistry \& Molecular Medicine, UC Davis School of Medicine, Sacramento, CA, USA \\ ${ }^{3}$ Department of Pathology, Roswell Park Cancer Institute, Buffalo, NY, USA \\ ${ }^{4}$ Department of Urology, UC Davis School of Medicine, Sacramento, CA, USA \\ ${ }^{5}$ Division of Hematology Oncology, UC Davis School of Medicine, Sacramento, CA, USA \\ ${ }^{6}$ Department of Internal Medicine, Comprehensive Cancer Center, UC Davis School of Medicine, Sacramento, CA, USA \\ Correspondence to: Ai-XiYu, email: yuaixi@whu.edu.cn \\ Ai-Ming Yu, email: aimyu@ucdavis.edu
}

Keywords: therapy, metastasis, doxorubicin, miR-34a, sorafenib, Pathology Section

Received: February 06, $2017 \quad$ Accepted: March 03, $2017 \quad$ Published: March 18, 2017

Copyright: Jian et al. This is an open-access article distributed under the terms of the Creative Commons Attribution License (CC-BY), which permits unrestricted use, distribution, and reproduction in any medium, provided the original author and source are credited.

\section{ABSTRACT}

Metastasis is a major cause of mortality for cancer patients and remains as the greatest challenge in cancer therapy. Driven by multiple factors, metastasis may not be controlled by the inhibition of single target. This study was aimed at assessing the hypothesis that drugs could be rationally combined to co-target critical DNA, RNA and protein molecules to achieve "saturation attack" against metastasis. Independent actions of the model drugs DNA-intercalating doxorubicin, RNA-interfering miR34a and protein-inhibiting sorafenib on DNA replication, RNA translation and protein kinase signaling in highly metastatic, human osteosarcoma 143B cells were demonstrated by the increase of YH2A.X foci formation, reduction of c-MET expression and inhibition of Erk1/2 phosphorylation, respectively, and optimal effects were found for triple-drug combination. Consequently, triple-drug treatment showed a strong synergism in suppressing 143B cell proliferation and the greatest effects in reducing cell invasion. Compared to single- and dual-drug treatment, triple-drug therapy suppressed pulmonary metastases and orthotopic osteosarcoma progression to significantly greater degrees in orthotopic osteosarcoma xenograft/spontaneous metastases mouse models, while none showed significant toxicity. In addition, tripledrug therapy improved the overall survival to the greatest extent in experimental metastases mouse models. These findings demonstrate co-targeting of DNA, RNA and protein molecules as a novel therapeutic strategy for the treatment of metastasis.

\section{INTRODUCTION}

Metastasis remains a major cause of death of cancer patients. Approximately $90 \%$ of cancer-associated mortality arises from systemic metastasis of the primary tumor [1-3]. As an example, osteosarcoma (OS), a primary locally destructive mesenchymal tumor accounting for $60 \%$ of malignant bone tumors among children and young adults, has a predilection for lung metastases [4$6]$. Improved therapies for OS have increased the 5-year survival rate to $60-70 \%$ for non-metastatic OS of the extremities [7-9], dramatically extending the life span of 
childhood OS survivors. However, the 5-years survival rate is only $18-33 \%$ for those with lung metastases at the time of diagnosis [9-11]. Overall $80 \%$ of OS patients die from distant metastases, most commonly in the lungs [9].

The processes such as invasion from the primary site, circulation of tumor-initiating cells, metastatic colonization, and distant outgrowth of metastases underlying cancer invasion-metastasis cascade are very complex [1-3]. While some molecular determinants and signaling pathways (e.g., c-MET, VEGF, Ras-RafMAPK-ERK pathways, etc.) behind cancer metastatic processes have been identified, much remains poorly understood. Furthermore, the presence of redundant signaling pathways and the emergence of complementary mechanisms and resistant phenotypes limit the efficacy of targeted anti-neoplastic therapies. Therefore, combating metastasis remains one of the greatest challenges in cancer therapy $[3,12]$ and blocking single target or pathway is unlikely to be very effective.

We recently established a novel platform for highyield production of biologic RNA-interfering (RNAi) agents including miRNAs and siRNAs $[13,14]$ that are distinguished from commonly used synthetic RNAi reagents carrying extensive artificial modifications [15]. We also demonstrated that biologic miR-34a prodrug was precisely processed to mature miR-34a and thus effective to regulate target gene expression (e.g., c-MET) [14, 16]. In addition, combination therapy with miR-34a prodrug and doxorubicin exerted synergistic effects in repressing human OS cell growth via RNA interference and DNA intercalation, and this combination is more effective than monotherapy in suppressing OS xenograft tumor growth [17].

To explore new strategy for the treatment of metastasis, we hypothesized that optimal outcomes might be achieved through "saturation attack", i.e., co-targeting of DNA, and particular RNA and protein molecules (Figure 1A) critical for almost all cancer cellular processes. To test the hypothesis, we employed DNA-intercalating doxorubicin, RNA-interfering miR$34 \mathrm{a}$, and protein kinase-inhibiting sorafenib as model drugs and assessed their independent and complementary actions in highly metastatic, human OS 143B model cells. Doxorubicin is one of the chemotherapeutic agents (i.e., methotrexate, doxorubicin, and cisplatin; sometimes with ifosfamide) that are currently used for the treatment of soft tissue sarcomas [7]. Since VEGFR and Raf/MEK/ ERK signaling pathways have been reported to be relevant to OS progression [18-20], sorafenib was chosen as a protein kinase-inhibiting model drug. Because miR-34a is significantly downregulated in human OS tissues [18, 19] and reintroduction of miR-34a into OS cells inhibits cell proliferation and suppresses tumorigenesis [20, 21], miR-34a was selected as an RNA-interfering agent. In addition, the biologic miR-34a prodrug used in this study was produced and folded in live cells [13, 14], which is distinguished from synthetic miRNA agents bearing extensive artificial modifications $[15,22]$. As a result, the combined drugs showed a strong synergism and the greatest effects in suppressing OS cell proliferation and invasion. In spontaneous and experimental metastasis mouse models, rational triple-drug combination therapy elicited the most beneficial outcomes, as manifested by the highest degrees of suppression of orthotopic OS progression and pulmonary metastases, as well as improvement of survival.

\section{RESULTS}

\section{Independent and combined actions of doxorubicin, sorafenib and miR-34a on target molecules in metastatic 143B cells}

To test the concept of co-targeting of critical DNA, RNA and protein molecules in metastatic cancer cells (Figure 1A), we first examined the effects of model drugs doxorubicin, miR-34a and sorafenib on corresponding targets and marker proteins in OS 143B cells and defined their interactions when used in combination. An immunofluorescent study was carried out to investigate $\gamma \mathrm{H} 2 \mathrm{~A}$.X foci formation, which is a sensitive and robust biomarker of DNA damage [23] induced by DNAintercalating drugs and may indicate the mechanistic actions of doxorubicin. Compared to 143B cells treated with vehicle, sorafenib plus miR-34a treatment did not alter $\gamma \mathrm{H} 2 \mathrm{~A} . \mathrm{X}$ signal intensity while doxorubicin alone sharply induced the damage of DNA (Figure 1B). Moreover, co-administration of sorafenib and miR-34a, alone or together, with doxorubicin sharply increased the levels of $\gamma \mathrm{H} 2 \mathrm{~A}$.X. The highest levels were observed in cells treated with doxorubicin plus miR-34a, with or without sorafenib (Figure 1B). The same results were obtained by Western blot analyses of $\gamma \mathrm{H} 2 \mathrm{~A}$.X (data not shown), indicating that sorafenib or miR-34a alone or combined does not alter $\gamma \mathrm{H} 2 \mathrm{~A}$.X foci formation but is able to largely enhance doxorubicin-provoked DNA damage in 143B cells.

Western blots were performed to verify the effects of miR-34a and sorafenib as well as combinatorial effects in 143B cells (Figure 1C). Compared to vehicle treatment, miR-34a led to a $40 \%$ suppression of c-MET protein levels, a well-defined miR-34a target [24-26] being involved in osteosarcoma metastasis [27-29]. To our surprise, either doxorubicin or sorafenib alone or in combination led to an upregulation of c-MET. However, co-administration of miR-34a abrogated the increase of c-MET expression caused by doxorubicin and sorafenib (Figure 1C). Likewise, the inhibitory effects of sorafenib on protein kinases [30-32] were indicated by an $80 \%$ reduction in phosphorylation of target Erk1/2, as revealed 
by Western blot analyses of p-Erk1/2 (Figure 1C). While doxorubicin and miR-34a alone caused $\sim 20 \%$ inhibition of p-Erk1/2 levels, triple-drug combination reduced p-Erk1/2 to a comparable level as sorafenib alone, which might had reached a saturation point. Together, the results confirmed the independent actions of doxorubicin, sorafenib and miR-34a in 143B cells as well as the ultimate combinatorial effects.

Synergism of doxorubicin, sorafenib and miR-34a in the suppression of $143 \mathrm{~B}$ cell proliferation

To define the combinatorial effects of doxorubicin, sorafenib and miR-34a in the inhibition of $143 \mathrm{~B}$ cell growth, we employed CellTiter-Glo Luminescent Cell Viability Assay to quantitate the anti-proliferative activities of individual drugs and various combinations. As expected, doxorubicin, sorafenib and miR-34a prodrug alone reduced the proliferation of $143 \mathrm{~B}$ cells in a dosedependent manner, and a dual- or triple-drug combination was more effective than individual agents (Figure 2A-2F). Interestingly, the anti-proliferation effects of sorafenib and miR-34a combination were mainly additive or even antagonistic at lower concentrations. In contrast, coadministration of doxorubicin with sorafenib or miR-34a or sorafenib plus miR-34a produced synergistic effects in suppressing the proliferation of 143B cells, where the synergism of triple-drug combination persisted at all concentrations (Figure 2F). Therefore, combination therapy could offer remarkable degrees of dose reduction, especially for doxorubicin and miR-34a prodrug, to achieve the same levels of anti-proliferation effects (Supplementary Figure S1A-D). For instance, an $80 \%$
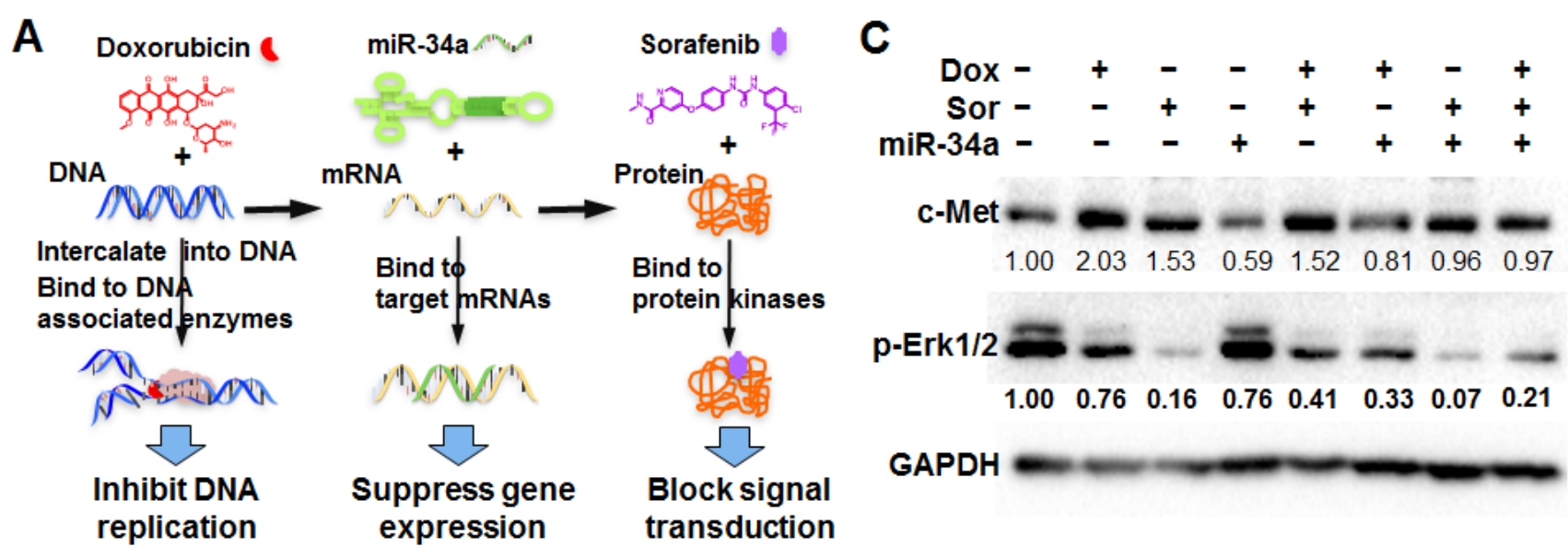

\section{GAPDH}
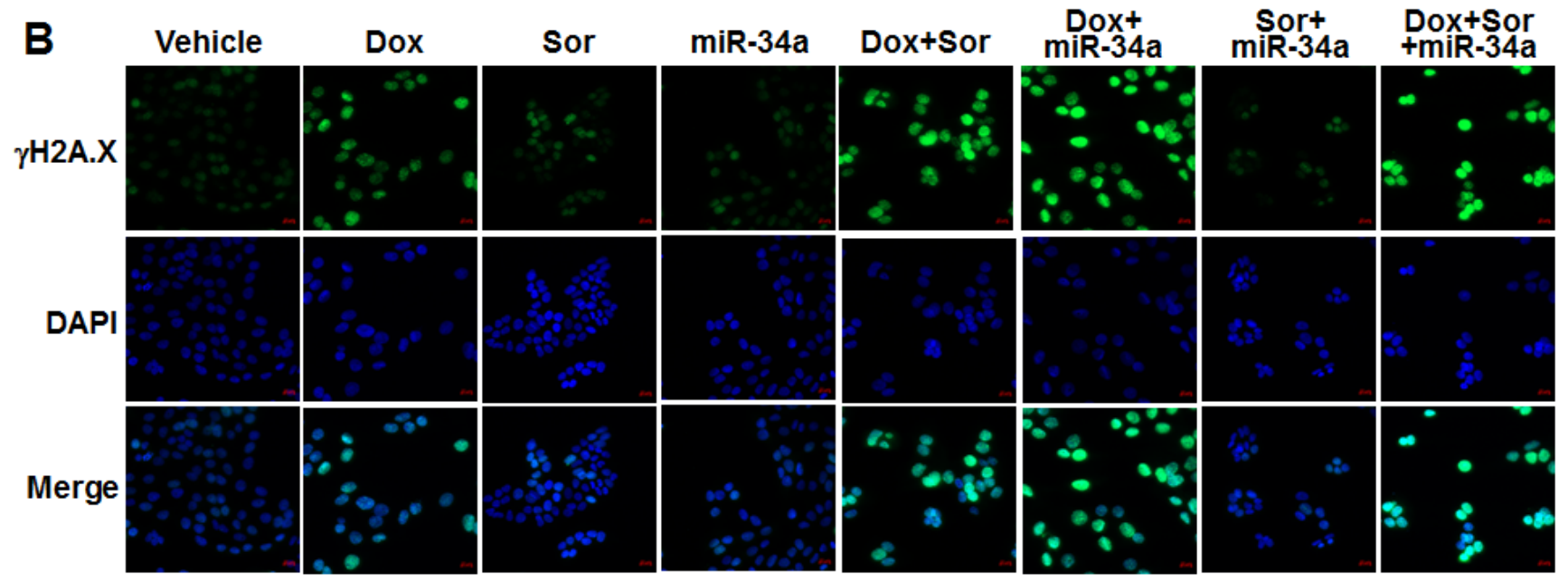

Figure 1: Independent and combined effects of triple drugs on DNA, mRNA and protein targets in highly metastatic osteosarcoma cells. A. Doxorubicin (Dox), bioengineered miR-34a prodrug (miR-34a) and sorafenib (Sor) were chosen as model drugs to target DNA and particular mRNAs and proteins, respectively. B. Immunofluorescent analysis of $\gamma \mathrm{H} 2 \mathrm{~A}$.X foci formation indicated Doxinduced DNA damage in 143B cells, which were enhanced to greater degrees with the addition of miR-34a or Sor. Cells were fixed at 24 $\mathrm{h}$ post-treatment and stained with specific $\gamma \mathrm{H} 2 \mathrm{~A} . \mathrm{X}$ antibody and then corresponding Alexa Fluor 488-conjugated antibody. Images were acquired with a confocal microscope. The bar indicates $20 \mu \mathrm{m}$. C. Immunoblot analysis of protein levels of p-Erk1/2 and c-Met confirmed the actions of Sor and miR-34a, respectively. Band density was determined by Image Lab software (Bio-Rad), and normalized to that of GAPDH. The protein levels in vehicle group were defined as 1.00 . 
inhibition requires approximately $25 \mathrm{nM}$ miR-34a alone or $160 \mathrm{nM}$ doxorubicin alone or $10,000 \mathrm{nM}$ sorafenib alone, whereas only $4 \mathrm{nM}$ miR-34a plus $40 \mathrm{nM}$ doxorubicin and 4,000 nM sorafenib in the triple-drug combination (Figure 2A-D). Moreover, there was a stronger synergism and much greater extent of dose reduction for doxorubicin at higher degrees of cell inhibition (e.g., $>75 \%$ ) when used with miR-34a or sorafenib or both, which would ultimately lessen or eradicate the risk of toxicity that might be induced by high doses of doxorubicin.

\section{Triple-drug combination with doxorubicin, sorafenib and miR-34a almost completely blocks the invasion potential of human 143B cells}

We further performed in vitro cell invasion assays to determine the impact of triple-drug combination on invasion potential of 143B cells (Figure 2G-2H) since invasion abilities of cancer cells are critical for the local destruction and metastasis of tumors. Our results showed that miR-34a alone suppressed the invasion capability of $143 \mathrm{~B}$ cells by about $50 \%$, and doxorubicin plus sorafenib reduced cell invasion by $74 \%$, as compared to the vehicle control. Furthermore, triple-drug combination with doxorubicin, sorafenib and miR-34a led to over $90 \%$ suppression of cell invasiveness, a significantly greater degree than miR-34a prodrug or doxorubicin plus sorafenib (Figure $2 \mathrm{H}$ ). The results demonstrate that tripledrug combination was the most effective to block the invasion ability of highly metastatic $143 \mathrm{~B}$ cells.

\section{Triple-drug therapy suppresses orthotopic osteosarcoma xenograft tumor progression and spontaneous pulmonary metastases to the greatest levels in mouse models}

We thus established an orthotopic osteosarcoma/ spontaneous metastases mouse model to determine the
A

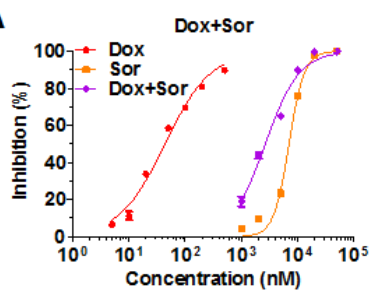

D

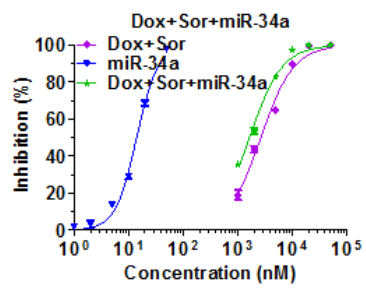

B

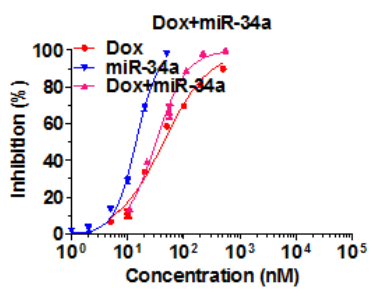

E

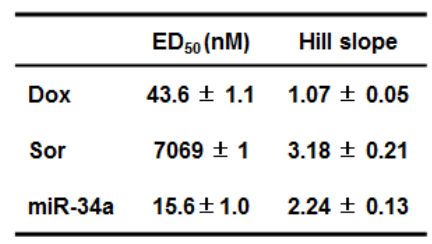

C

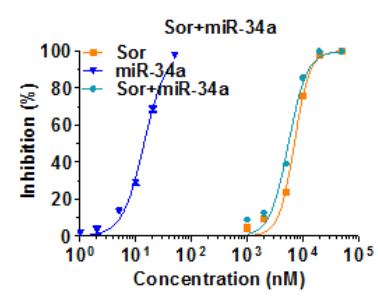

$\mathbf{F}$

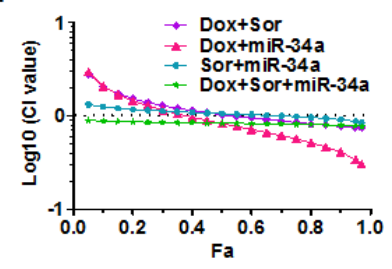

$\mathrm{H}$

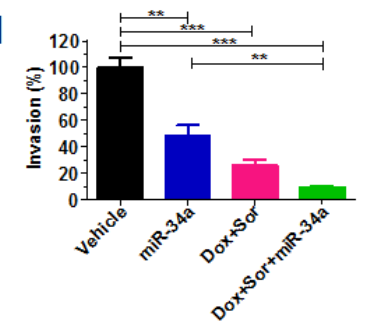

Figure 2: Doxorubicin, sorafenib and miR-34a produced synergism and the greatest effects in suppressing cancer cell proliferation and invasion. Dose-response curves for Dox and Sor A., Dox and miR-34a B., Sor and miR-34a C., and Dox plus Sor and miR-34a D., alone or in combination (Dox: Sor: miR-34a = 10:1000:1; thus the X-axis indicates the combined drug concentrations), in the inhibition of human osteosarcoma 143B cell proliferation. Cells were treated with various concentrations of Dox, Sor, and miR34a alone or in combination. Cell viability was determined using CellTiter-Glo luminescent cell viability assay at $72 \mathrm{~h}$ post-treatment. E. Estimated pharmacodynamic parameters for Dox, Sor and miR-34a in the suppression of 143B cell proliferation. Values are mean \pm SD of quadruplicate treatments. F. Chou-Talalay (Fa-CI) plot demonstrated the synergistic effects for Dox, Sor and miR-34a in the suppression of $143 \mathrm{~B}$ cell proliferation. G. and H. The invasion capability of $143 \mathrm{~B}$ cells was inhibited to the greatest extent by the triple-drug treatment. $72 \mathrm{~h}$ post-treatment, cells were subjected to Matrigel invasion assay for $30 \mathrm{~h}$, fixed with $10 \%$ formalin, and then stained with $0.1 \%$ crystal violet. Images $(\mathrm{G} ; 40 \times)$ were acquired with an Olympus IX2-UCB microscope, and invasion capabilities $\mathbf{H}$. were compared for different treatments. Values are mean $\pm \mathrm{SD}$ of triplicate treatments. ${ }^{*} P<0.01$, and $* * * P<0.001$ (one-way ANOVA with Bonferroni post tests). 
effectiveness of rationally-designed triple-drug therapy in the suppression of xenograft tumor growth (Figure 3 ) and reduction of spontaneous pulmonary metastases (Figure 4). The sizes of orthotopic xenograft osteosarcomas were monitored over time through bioluminescence imaging and by caliper. Our data showed that every drug treatment could significantly inhibit the outgrowth of viable xenograft osteosarcomas than vehicle control, albeit to different degrees, as manifested by bioluminescence intensities (Figure 3B) and calculated tumor volumes (Figure 3C). The degrees of suppression by triple-drug therapy were significantly greater than sorafenib plus either doxorubicin or miR-34a treatment (Figure 3C). Although statistical significance was not reached when triple-drug therapy group was compared to doxorubicin plus miR-34a treatment, the greatest extent of repression of osteosarcoma progression by triple therapy was obvious (Figure 3C). The consistent tendency was also indicated by visual inspection of dissected xenograft osteosarcomas (Figure 3D) and quantitative measurement (Figure 3E) of tumor weights.

To evaluate the effects of individual treatments on pulmonary metastases, lung tissues were dissected from all mice and GFP-expressing tumors were imaged. As demonstrated by ex vivo GFP signals including the distributions and intensities (Figure 4A), triple-drug combination therapy showed a much greater suppression of pulmonary metastases. We thus randomly selected four samples from each group for histopathological analyses, among which triple therapy group consistently showed

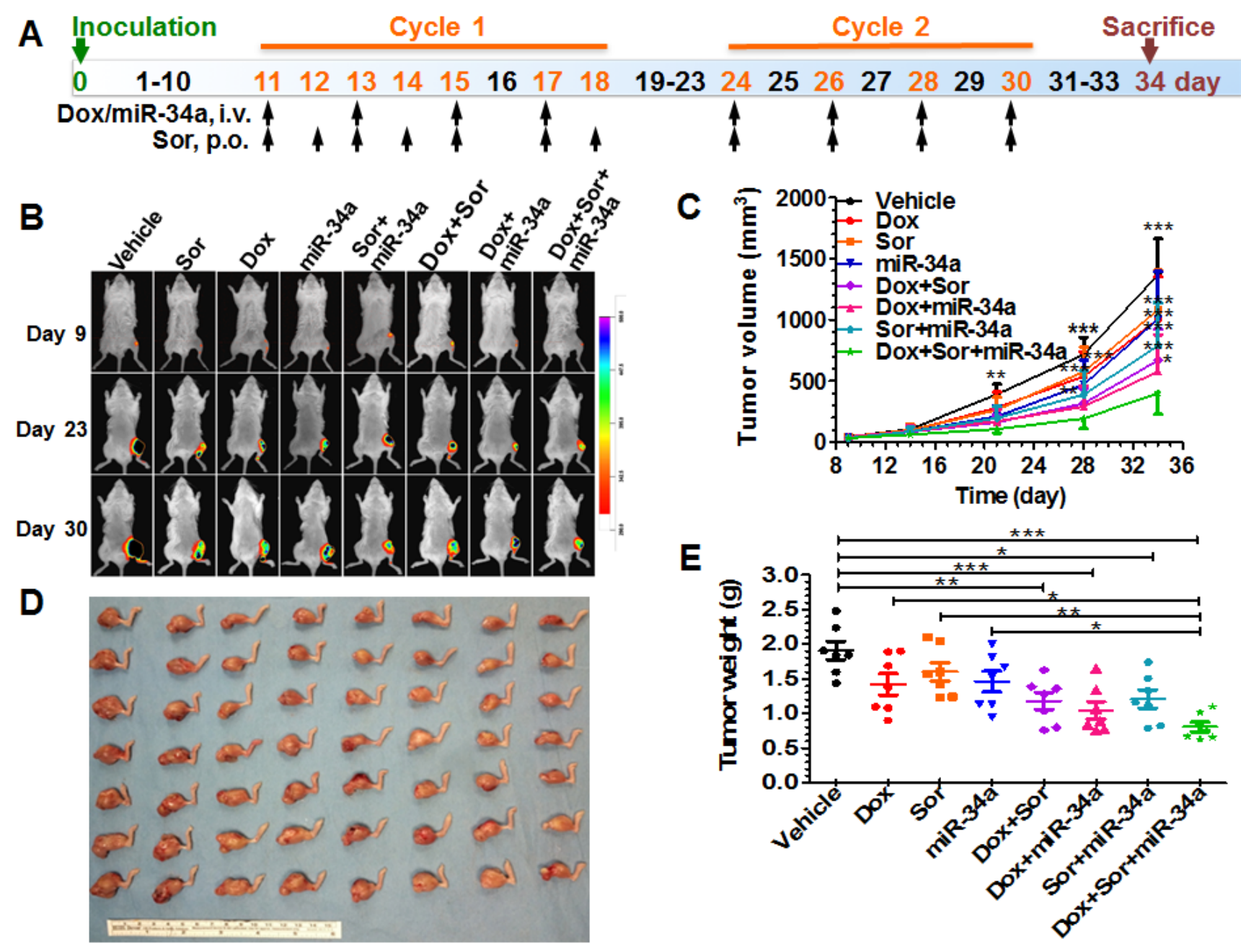

Figure 3: Triple-drug therapy was the most effective in suppressing tumor growth in orthotopic, metastatic osteosarcoma xenograft mouse models. A. Scheme of therapy study in mouse models including osteosarcoma cell inoculation and drug treatment. B. Comparison of bioluminescent signals of orthotopic xenograft tumors on day 9, 23, and 30 among different treatment groups. C. Xenograft tumor growth was reduced to a significantly greater degree by triple therapy than vehicle or Dox, Sor, mir-34a alone, or Dox plus Sor, or Sor plus miR-34a $(* P<0.05, * * P<0.01$, and $* * * P<0.001$ as compared to triple treatment; two-way ANOVA with Bonferroni post tests). D. Visual comparison of dissected orthotopic osteosarcoma tumor tissues from mice with different treatments. E. Weights of the dissected xenograft tumors $(* P<0.05, * * P<0.01$, and $* * * P<0.001$; one-way ANOVA with Bonferroni post tests). Values are mean $\pm \mathrm{SD}(\mathrm{N}=7$ per group). 
the least lung metastases (Figure 4B). Specifically, the numbers of metastases per lung sample were much less in triple-drug therapy groups (1-4 foci of metastases in each lung) than vehicle control group (9-34 foci) (Figure 4C). In addition, the sum of the longest diameters of metastasis foci in triple-drug therapy group as well as doxorubicin/ miR-34a treatment group was significantly smaller than vehicle control (Figure 4D). Together, the results demonstrated that triple-drug therapy using doxorubicin, miR-34a and sorafenib provided the greatest degrees of protection against orthotopic osteosarcoma progression and pulmonary metastases.

\section{Triple-drug combination therapy is well tolerated in tumor-bearing mice}

Following the first course of treatment (Figure 3A) mouse body weights decreased to different degrees, which was more obvious in doxorubicin-treated groups (Figure 5A) and might indicate some doxorubicin-associated toxicity. However, all mice did not show any signs of stress such as hunched posture or labored movement. After fiveday recovery showing gain of body weights (Figure 5A), the second course of treatment was initiated with slightly reduced drug doses to avoid any potential adverse effects. After this treatment, all mice including those treated with vehicle showed 5-10\% loss of body weights (Figure 5A), likely due to the progression of osteosarcoma (Figure 3), severe metastases burden (Figure 4) and/or handling rather than drug treatment. There was actually one mouse in the vehicle treatment group that showed the greatest degree of body weight loss at the last week of study, which was mainly attributable to cancer-associated cachexia resulting from advanced osteosarcoma.

To examine the risk of hepatic and renal toxicities, serum samples were collected and subjected to blood chemistry profiling (Figure 5B-5F). Levels of alanine
A

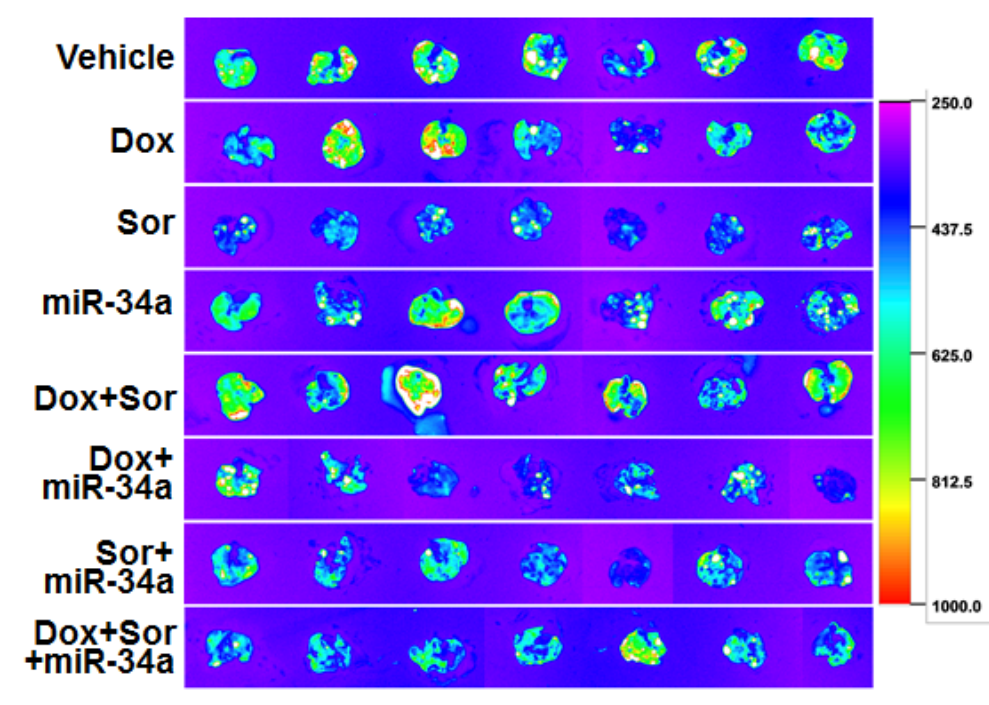

B

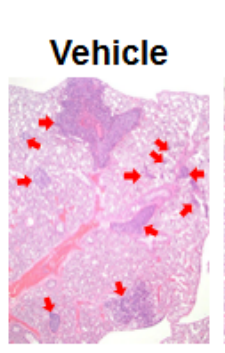

Dox

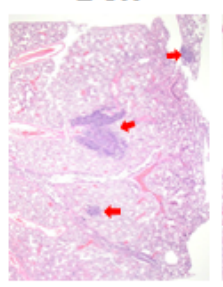

Sor

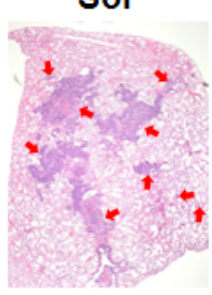

miR-34a

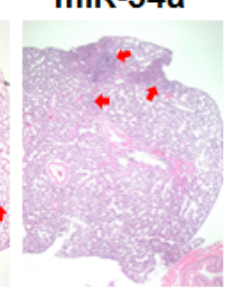

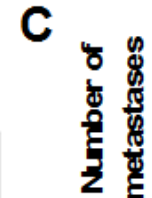
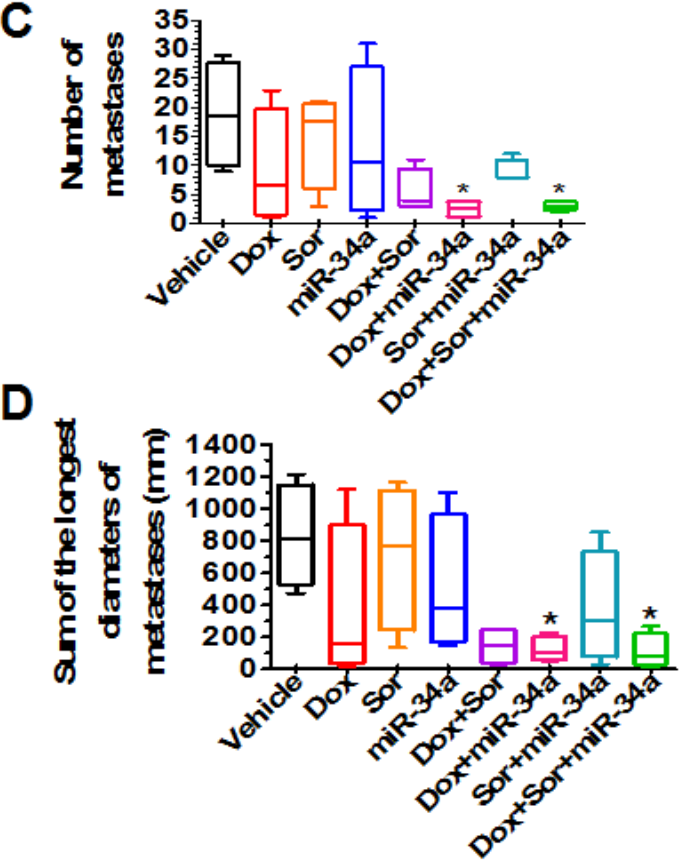

Dox+Sor
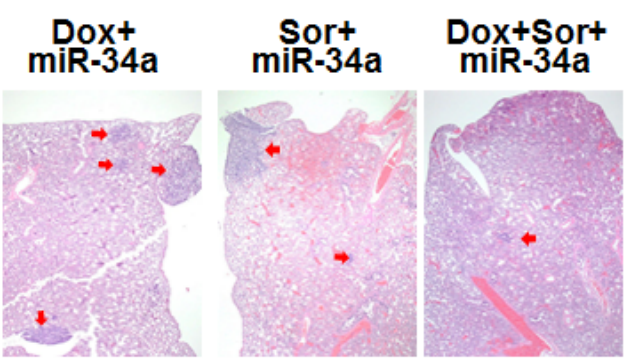

Figure 4: Doxorubicin, sorafenib and miR-34a triple-drug therapy sharply reduced pulmonary metastases from orthotopic osteosarcomas in mouse models. A. Comparison of ex vivo GFP images of lung metastases between different treatment groups $(\mathrm{N}=7$ per group). B. H\&E histology $(40 \times)$ showed a much lower degree of tumor metastases (red arrow) for lung tissues dissected from mice under triple drug combination therapy. C. and D. Comparison of the numbers of lung metastases and sum of the longest diameters of lung metastases, respectively, between different treatments. The boxes extend from the 10th to the 90th percentile, the lines indicate the median values, and the whiskers indicate the range of values. $* P<0.05$ as compared to vehicle control group ( $\mathrm{N}=4$ per group). 
aminotransferase (ALT), aspartate aminotransferase (AST), total bilirubin, both blood urea nitrogen (BUN) and creatinine concentrations were all variable in individual treatment groups but within the normal ranges (except the cachectic mouse described above), the latter of which indicates the absence of liver and kidney toxicity. In addition, serum cardiac troponin I (cTnI) levels [33] were examined using an ELISA assay for the assessment of risk of doxorubicin-associated myocardial damage. Our data showed that cTnI levels in control and treatment groups were all under the lower limit of quantification $(0.156 \mathrm{ng} /$ $\mathrm{ml}$ ), suggesting the lack of cardiac toxicity. Together, these results indicated that therapeutic doses of doxorubicin, sorafenib and miR-34a prodrug alone or in combination were well tolerated in these mice.

\section{Triple-drug combination therapy improves the overall survival to the greatest degree in experimental metastases mouse models}

To further define the benefits of triple therapy for the treatment of late-stage metastases, we established an artificial pulmonary metastases mouse model via intravenous injection of 143B OS cells (Figure 6A). Metastases were confirmed to be visible on the surface of all mouse lung tissues at about 2 weeks post-inoculation in our pilot study. Therefore, we started the treatment with vehicle, miR-34a, doxorubicin/sorafenib, and the triple-drug combination on day 13 post-inoculation (Figure 6A). The survival study was terminated on day 70 when all mice treated with vehicle or doxorubicin/ sorafenib died (Figure 6B). The presence of extensive pulmonary metastases after death or euthanasia was verified by necropsy and histological analyses (Figure 6C). Furthermore, extrapulmonary metastases (e.g., skull, jaw, shoulder, knee or/and caudal vertebra) were noted in 3 mice among each group treated with vehicle, miR-34a or doxorubicin plus sorafenib, in contrast to 2 mice treated with triple-drug combination.

While doxorubicin plus sorafenib therapy or miR34a alone significantly increased the overall survival and improved the median survival from 38 days to 54 days, triple-drug combination therapy improved the overall survival to a more significant level and extended the median survival to an even longer time (60.5 days;

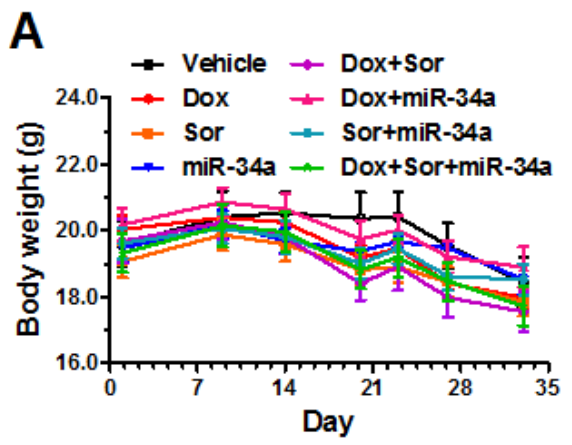

D

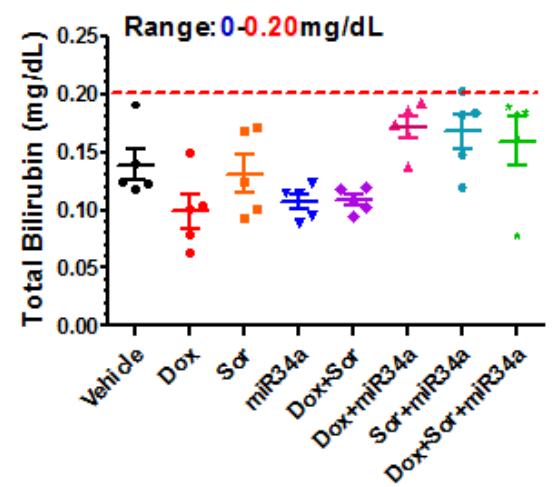

B

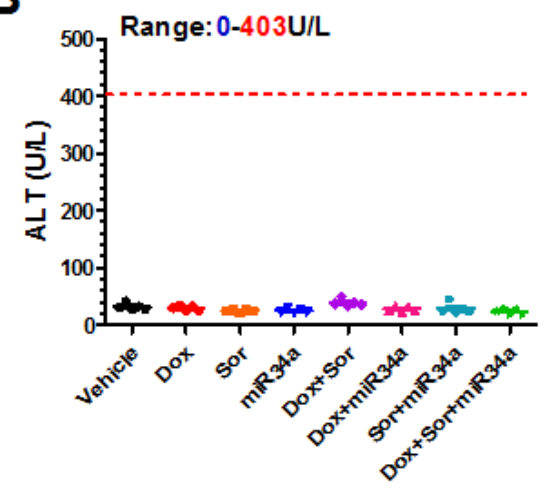

E

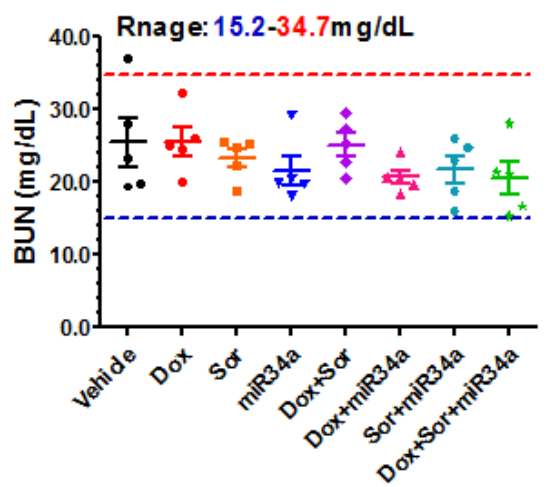

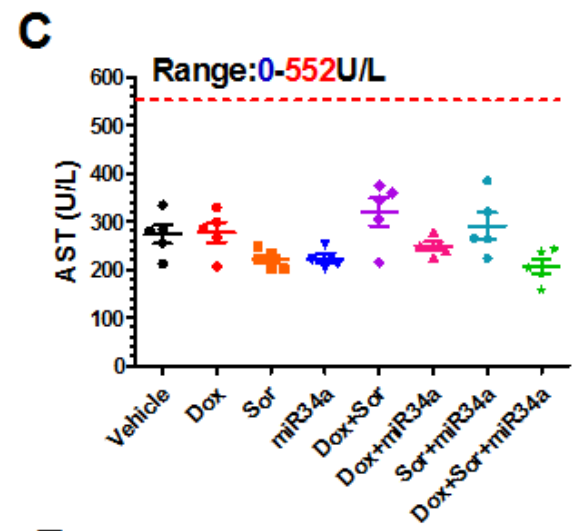

$\mathbf{F}$

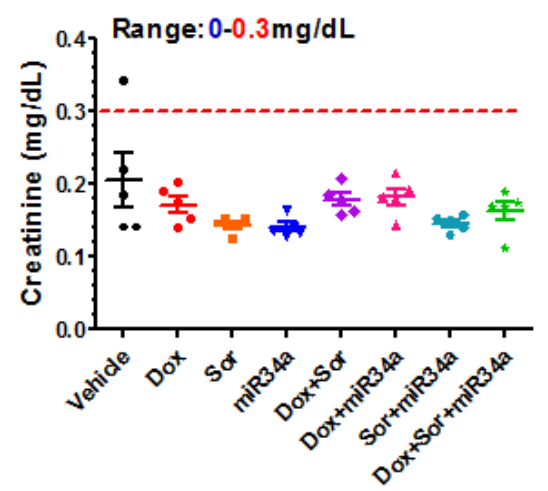

Figure 5: Triple-drug combination therapy was well tolerated in mice. Compared to vehicle control group, systemic (co-) administration of doxorubicin, sorafenib and bioengineered miR-34a prodrug had no significant impact on mouse body weights A. and blood chemistry profiles including alanine transaminase (ALT; B.), aspartate transaminase (AST; C.), total bilirubin D., blood urea nitrogen (BUN; E.), and creatinine F. levels. Values are mean $\pm \mathrm{SD}(\mathrm{N}=5$ in each group). The ranges of individual blood chemistry biomarkers (derived from BALB/c mice; Comparative Pathology Laboratory at UC-Davis) were marked as references. In addition, cTnI levels in all mice were below the lower limit of quantification $(0.156 \mathrm{ng} / \mathrm{ml})$, indicating the absence of cardiac toxicity. 
Figure $6 \mathrm{~B})$. In contrast to the death of all mice treated with vehicle control by day $56,50 \%$ of the mice under triple-drug therapy were still alive on day 56 and $25 \%$ of mice were alive at the termination of the study (Figure 6B) even though palpable pulmonary metastases were identified (Figure 6C). These results demonstrated that triple-drug therapy with DNA-intercalating doxorubicin, RNA-interfering miR-34a and protein kinase-inhibiting sorafenib could ultimately extend the survival.

\section{DISCUSSION}

Treating lethal metastasis might not be feasible through the inhibition of single target or pathway due to the presence of multiple and/or complementary mechanisms underlying complex cancer invasion-metastasis cascade [3]. In contrast, combination therapy has been proved as an effective means to fight against metastatic cancers [12]. Nevertheless, present combination therapies all focus on the co-inhibition of protein targets. For instance, the first immune checkpoint inhibitor combination approved by FDA in October, 2015 for the treatment of unresectable or metastatic BRAF $\mathrm{B}^{\mathrm{V} 60}$ wild-type melanoma consists of nivolumab and ipilimumab, which target the programmed cell death protein 1 and cytotoxic $\mathrm{T}$ lymphocyte antigen
4, respectively [34]. In this study, we demonstrated a new strategy to combat metastasis, which utilizes multiple drugs to co-target DNA, mRNA and protein molecules critical for many cellular processes. The benefits of "saturation attack" were strikingly obvious, given the greatest degrees in the suppression of orthotopic osteosarcoma progression and lung metastases, as well as improvement of survival in spontaneous and experimental metastases mouse models, which were attributable to the independent and complementary or combined actions of model drugs on DNA replication, mRNA translation, and protein signal transduction in cells.

Doxorubicin, biological miR-34 prodrug, and sorafenib were chosen as model drugs to target DNA, RNA and protein molecules, respectively. The mechanistic actions of individual model drugs on DNA replication, target mRNA translation, and protein signal transduction were illustrated by an increased $\gamma \mathrm{H} 2 \mathrm{~A} . \mathrm{X}$ foci formation, reduced c-MET expression, and decreased Erk1/2 phosphorylation, respectively, in human OS 143B cells, which carry a $p 53$ mutant and show high levels of p53 protein expression commonly identified in human malignant OS, thus representing a clinically-relevant OS cell model $[35,36]$. While sorafenib or/and miR-34a alone had no or minimal effects on $\gamma \mathrm{H} 2 \mathrm{~A}$.X foci formation, both
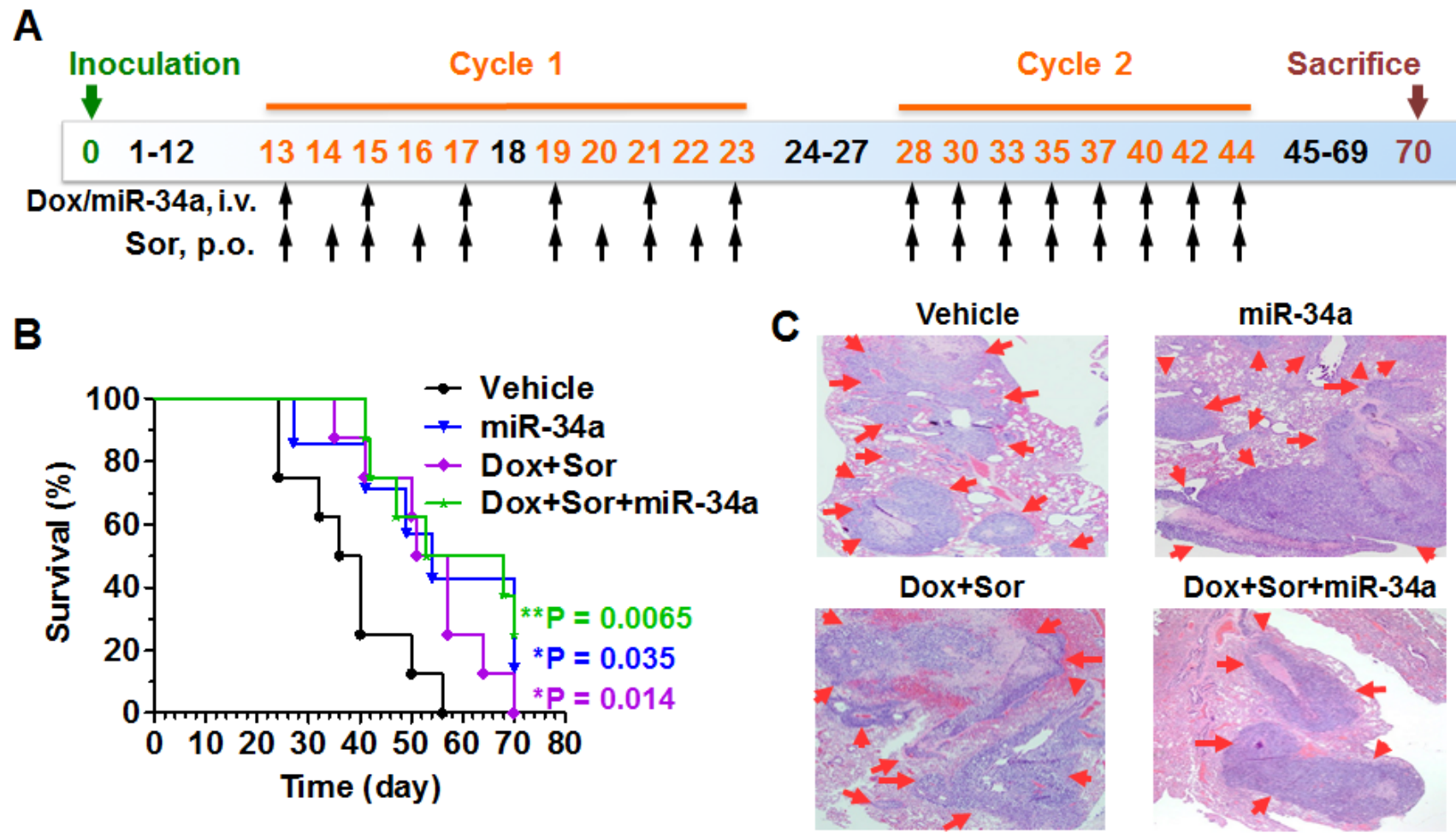

Figure 6: Triple-drug therapy improves overall survival to the greatest level in experimental lung metastases mice. A. Timeline of osteosarcoma cell inoculation to produce artificial pulmonary metastases mouse models, and drug treatment. B. Survival analysis showed that mice in treatment groups lived much longer than vehicle control $(* P<0.05, * * P<0.01 ; \mathrm{N}=7-8$ per group; Log-rank (Mantel-Cox) Test). Median survival was 38 days for mice treated with vehicle, 54 days for miR-34a alone, 54 days for doxorubicin (Dox) plus sorafenib (Sor), and 60.5 days for doxorubicin, sorafenib plus miR-34a triple-drug therapy. C. H\&E histology $(40 \times)$ confirmed that mouse lungs were severely eroded by the tumor metastases (red arrow). 
could largely enhance doxorubicin-provoked DNA damage in $143 \mathrm{~B}$ cells. By contrast, the reduction of pErk $1 / 2$ levels by sorafenib alone seemed to reach the maximal effects as the addition of doxorubicin and miR-34a did not show any impact. Consistent with the upregulation of c-MET in ovarian and hepatocellular carcinoma cells by doxorubicin and sorafenib that may be linked to drug resistance [37, 38], our data revealed higher levels of c-MET in OS cells treated with doxorubicin and sorafenib, alone or in combination. However, the inclusion of c-MET mRNAtargeting miR-34a completely erased such negative impact of doxorubicin and sorafenib, highlighting the benefits of independent and complementary actions of rationallycombined DNA-intercalating, RNA-interfering, and protein-inhibiting drugs.

The strong synergism of doxorubicin, sorafenib and miR-34a allowed high degrees of dose reduction of individual drugs to achieve the same level of efficacy (e.g., $\mathrm{Fa}=0.8$ ). This is of particular important for chemotherapeutic doxorubicin and RNAi drug miR-34a, which at higher doses might induce cardiotoxicity and immune responses, respectively. As a result, relatively lower doses of individual drugs, alone or in combination, were utilized to evaluate saturation attack strategy in the mouse model of pulmonary metastases from orthotopic OS xenografts, which resembles the clinical features of human OS for the evaluation of new therapeutic strategies $[3,39]$. Besides the body weight loss caused by severe tumor burden (vehicle control), drug-associated body weight loss was noted but acceptable in all treatment groups. Furthermore, the drug-/injection-induced body weight was restorable after withdrawal. All mice showed normal blood chemistry profiles, except for one mouse in the vehicle control group with cancer-related cachexia and abnormal blood BUN and creatinine levels, indicating that therapeutic doses of doxorubicin, sorafenib and bioengineered miR-34a prodrug were well tolerated in tumor-bearing mice without causing any liver or kidney toxicity. In addition, no mice showed any cardiac injury, as determined by the levels of cTnIs. This may be due to the use of much lower doses of doxorubicin in the present study, although it is unknown if co-administration of miR-34a prodrug would give rise to asymptomatic heart dysfunction of doxorubicin plus sorafenib [40].

The benefits of triple-drug therapy via co-targeting DNA, RNA and protein molecules were notably demonstrated by the greatest level of efficacy in the spontaneous metastases mouse models. Compared to vehicle control, single drug treatment offered a lower degree of suppression of orthotopic OS xenograft tumor growth and showed insignificant effects on pulmonary metastases. In addition to consistent findings on the effectiveness of doxorubicin chemotherapy plus miR34a replacement therapy on OS xenograft tumor growth [17], present study revealed much greater degrees of suppression by the combination of doxorubicin plus sorafenib, and sorafenib plus miR-34a than single drug treatment. Furthermore, co-administration of doxorubicin and miR-34a significantly suppressed lung metastases in these mice although the combinations of sorafenib plus miR-34a and doxorubicin plus sorafenib only had modest effects. Most importantly, the greatest degree of suppression of orthotopic OS xenograft tumor growth and pulmonary metastases were identified in mice treated with triple-drug combination. The optimal therapeutic outcomes from saturation attack observed in vivo are also consistent with the synergistic effects in the control of cell proliferation and the blockage of invasiveness identified in vitro.

The present study further revealed the benefit of triple-drug therapy in experimental metastasis mouse model, as indicated by the extents of improvement of survival. Consistent with the encouraging results of doxorubicin plus sorafenib therapy for advanced HCC patients [40], dual-drug combination was able to significantly improve the survival of pulmonary metastatic mice. Furthermore, two cycles of monotherapy with bioengineered miR-34a prodrug significantly improved the survival rate of mice. This is in agreement with sufficient distribution of in vivo-jetPEI-encapsulated miR-34a prodrug to mouse lung tissues (unpublished data) and the actions of miR-34a on multiple therapeutic targets including PD-L1 implicated in immunotherapy [41, 42]. The triple-drug combination therapy enhanced mouse survival rate to the most significant level, which was also indicated by the longest median survival. The absence of statistical differences between triple-drug combination therapy and miR-34a alone or doxorubicin/sorafenib is likely due to a quite heavy burden of lung metastases in the experimental animal models and relatively small sample size in each group.

In summary, we have demonstrated that a rational triple-drug combination therapy can offer robust and optimal outcomes in spontaneous and experimental metastases mouse models, as manifested by the greatest degrees of suppression of tumor progression and metastasis as well as extension of overall survival. Independent and combined actions of model drugs doxorubicin, miR-34a and sorafenib on the inhibition of DNA replication, RNA translation and protein signal transduction are indicated by the increase of $\gamma \mathrm{H} 2 \mathrm{~A} . \mathrm{X}$, decrease of c-MET expression and reduction of ERK1/2 phosphorylation, respectively. Although the identification of optimal dose regimens for direct clinical application will be challenging, rational combination therapy offers obvious synergism and permits the use of much lower and safe doses of drugs. Our findings suggest that co-targeting critical DNA, RNA and protein molecules may provide a framework for developing new strategies for the treatment of the deadliest metastases. 


\section{MATERIALS AND METHODS}

\section{Materials}

Doxorubicin (hydrochloride salt, $>99 \%$ ) and sorafenib (p-toluenesulfonate salt, > 99\%) were purchased from LC Laboratories (Woburn, MA, USA). RPMI 1640 medium, trypsin and phosphate-buffered saline (PBS), fetal bovine serum, opti-MEM, BCA Protein Assay Kit, and Lipofectamine 3000 Transfection Kit were bought from Thermo-Fisher Scientific Inc (Waltham, MA, USA). RIPA buffer was bought from Sigma-Aldrich (St. Louis, MO, USA) and protease inhibitor cocktail was from Roche Diagnostics (Mannheim, Germany). Bovine Serum Albumin and in vivo-jetPEI were purchased from VWR (Visalia, CA, USA). ECL substrate and PVDF membrane were supplied by Bio-Rad (Hercules, CA, USA). Crystal violet was bought from MP Biomedicals, LLC (Solon, OH, USA). Manufacturers of antibodies used for western blot and immunofluorescence were shown in Supplementary Table S1. All other chemicals and organic solvents of analytical grade were purchased from SigmaAldrich or Thermo-Fisher Scientific Inc.

\section{Biologic miR-34a prodrug}

Bioengineered miR-34a prodrug (tRNA/pre-miR34a) was expressed in E. coli (strain HST08) and purified by an anion exchange fast protein liquid chromatograph (FPLC) method, as described [13, 14, 43]. The purity of miR-34a prodrug was assessed by denaturing urea polyacrylamide gel electrophoresis (PAGE) and determined quantitatively by high performance liquid chromatography (HPLC) analysis [14]. Endotoxin activities were determined using the Pyrogent-5000 kinetic LAL assay (Lonza) by following the instructions. The miR-34a prodrugs over $98 \%$ pure and less than $10 \mathrm{EU} /$ $\mu \mathrm{g}$ RNA were used in the following study. Lipofectamine 3000 and in vivo-jetPEI were used for the delivery of miR$34 \mathrm{a}$ to cells and animals, respectively.

\section{Human cell lines}

The human OS cell lines 143B (CRL-8303) was bought from American Type Culture Collection (Manassas, VA, USA) and cultured in RPMI 1640 medium containing 10\% FBS. The luciferase and GFP-expressing 143B-GFP-Luc cells were generated after transduction with pCCLc-Luc-EGFP lentiviral constructs (Vector Core, UC Davis Medical center, Sacramento CA).

\section{Cell viability assay, dose-response relationship and synergism}

143B-GFP-Luc cells $\left(5 \times 10^{3}\right.$ cells/well $)$ were seeded in 96-well plate overnight and then treated with different concentrations of doxorubicin $(0,5,10,20$, $50,100,200,500 \mathrm{nM})$, sorafenib $(0,1,2,5,10,20,50$ $\mu \mathrm{M})$, miR-34a prodrug $(0,1,2,5,10,20,50 \mathrm{nM})$ or the combination in fixed ratio (doxorubicin: sorafenib: miR-34a, 10:1000:1). After 72 hours, cell viability was determined by CellTiter-Glo Luminescent Cell Viability Assay (Promega, Madison, WI, USA). The degrees of inhibition were calculated by adjusting the vehicle control group to $0 \%$ and dose-response curves were established by plotting inhibition versus drug concentration. Cells were treated in quadruplicate and assayed separately. Data were fit to a normalized inhibitory dose-response model with variable slope $\left(\mathrm{Y}=100 /\left(1+10^{\wedge}((\operatorname{LogEC} 50-\mathrm{X}) *\right.\right.$ HillSlope $)$; GraphPad Prism, San Diego, CA) for the estimation of EC50, Hill slope, and Bottom values.

The Chou-Talalay approach [44] was employed to further analyze interactions of these three drugs in the inhibition of human OS 143B-GFP-Luc cell growth. For triple therapy, doxorubicin and sorafenib were used as an entirety to combine with miR-34a. The combination index $(\mathrm{CI})$ values at each fraction affected $(\mathrm{Fa})$ were calculated with CompuSyn software (ComboSyn, Inc., USA) to define the combinational effects, i.e., $\mathrm{CI}<1$ indicates synergism, $\mathrm{CI}=1$ indicates additivity, and $\mathrm{CI}>1$ indicates antagonism. In addition, the dose reduction index (DRI) values were calculated for the evaluation of dose reduction levels in combination therapy [44].

\section{Invasion assay}

Invasive potential of 143B-GFP-Luc cells, treated with vehicle, or $12 \mathrm{nM}$ miR-34a, or $40 \mathrm{nM}$ doxorubicin plus $4 \mu \mathrm{M}$ sorafenib, or the combination for $72 \mathrm{~h}$, was assessed as described previously [16, 17, 45] by using Corning BioCoat Matrigel Invasion Chamber with 8.0 $\mathrm{mm}$ PET membrane coated with matrigel (Corning, NY, USA). Briefly, $5 \times 10^{4}$ cells in $500 \mu 1$ serum-free RPMI 1640 media were placed into the upper insert, and 750 $\mu \mathrm{l}$ medium supplemented with $10 \%$ FBS was added into the well as a chemo-attractant. $30 \mathrm{~h}$ later, cells in the upper inserts were removed and the lower were fixed with $10 \%$ formalin, stained with $0.1 \%$ crystal violet, and then photographed with five fields per insert under an Olympus IX2-UCB microscope $(40 \times$ magnifications $)$. Each treatment group was conducted in triplicate and assessed independently. The quantification of invaded cells was calculated using Image $\mathbf{J}$ software and invasion capacity was determined by adjusting the vehicle control group to $100 \%$. 


\section{Immunofluorescence study on $\gamma \mathrm{H} 2 \mathrm{~A}$.X foci}

143B-GFP-Luc Cells $\left(1 \times 10^{5}\right.$ per well $)$ were plated into 6-well plates with coverslips on the bottom and then treated with vehicle, doxorubicin (40 nM), sorafenib (4 $\mu \mathrm{M})$ and miR-34a (12 $\mathrm{nM})$ alone or in combination on the next day. 24 hours later, cells were fixed with $10 \%$ formaldehyde for $15 \mathrm{~min}$ at room temperature, rinsed three times in PBS, and blocked for $1 \mathrm{~h}$ in PBS consisting of $2 \%$ bovine serum albumin $/ 0.3 \%$ Triton X-100 (Fisher Scientific) at room temperature. After rinsed three times in PBS, cells were incubated with anti- $\gamma \mathrm{H} 2 \mathrm{~A} . \mathrm{X}$ (Ser139) antibody (1:800, Cell Signaling Technology, Danvers, MA) overnight at $4{ }^{\circ} \mathrm{C}$. After washed with PBS for 3 times, cells were incubated in Alexa Fluor ${ }^{\circledR} 488$-conjugated goat anti-rabbit IgG (1:800, Cell Signaling Technology) for $1 \mathrm{~h}$ at room temperature in dark. Nucleus was counterstained with DAPI using Prolong ${ }^{\circledR}$ Gold Antifade Reagent (Cell Signaling Technology). Images were taken with a Zeiss Axio Observer.z1 Microscope coupled to a Zeiss LSM 710 Scanning Device (Zeiss, Oberkochen, Germany).

\section{Protein isolation and immunoblot analysis}

Human OS 143B-GFP-Luc cells were treated with doxorubicin $(40 \mathrm{nM})$, sorafenib $(4 \mu \mathrm{M})$ and miR-34a (12 $\mathrm{nM}$ ) alone or in combination. Cells were collected at 72 $\mathrm{h}$ post-treatment and lysed in RIPA buffer containing protease inhibitor cocktail. Following determination of protein concentrations with a BCA Protein Assay Kit, protein samples $(30 \mu \mathrm{g} / \mathrm{lane})$ were loaded and separated on a $10 \%$ SDS-PAGE gel and transferred onto PVDF membranes. Membranes were incubated with anti-c-MET (1:200; C-28; Santa Cruz, Dallas, Texas), anti-p-Erk1/2 (1:1000; Thr202/Tyr204; Cell Signaling Technology), or anti-GAPDH (1:2,000; FL-335; Santa Cruz) rabbit antibody, and then with a peroxidase goat anti-rabbit IgG (Jackson ImmunoResearch Inc., West Grove, PA, USA). After incubation with Clarity Western ECL substrates (Bio-Rad, Hercules, CA, USA), the proteins were visualized with the ChemiDoc MP Imaging System (BioRad) and quantified by Image Lab software (Bio-Rad). GAPDH was used as a loading control.

\section{Animal models and therapy studies}

All animal procedures were approved by the Institutional Animal Care and Use Committee of University of California, Davis, and all animal studies were conducted in accordance with the relevant national and international guidelines. Non-obese diabetic/ severe combined immunodeficient (NOD/SCID) mice (NOD. CB17-Prkdescid/J) were purchased from Jackson Laboratory and adaptively fed at least one week before experiments. Animals were randomly assigned to treatment groups and closely monitored. Mice were euthanized if tumor size reached $2,000 \mathrm{~mm}^{3}$ (roughly $10 \%$ baseline body weight) or exceeded $2 \mathrm{~cm}$ in any direction, or body weight decreased $20 \%$, otherwise, they were euthanized at the end of the study.

To establish orthotopic osteosarcoma xenograft/ spontaneous metastasis mouse models, 143B-GFPLuc cells $\left(7.2 \times 10^{5}\right.$ cells suspended in $40 \mu 1$ PBS $)$ were injected into the right tibia of anesthetized 7-week-old female mice $[36,46]$. Tumor growth was monitored by bioluminescence imaging and measured with a caliper. In particular, tumor volume was calculated using the formula, tumor volume $\left(\mathrm{mm}^{3}\right)=($ length + width $) \times$ length $\times$ width $\times$ $0.2618[16,36]$. For bioluminescent imaging, D-luciferin $(150 \mathrm{mg} / \mathrm{kg})$ (BioVision, Inc. Milpitas, CA, USA) was injected into the abdominal cavity of anesthetized mice immediately before imaging. Images were acquired by KODAK Image Station 4000 Digital Imaging Systems and analyzed by Carestream Molecular Imaging Software 5.4.2 (Carestream Health, Inc.). On day 11 after inoculation, 56 mice were divided into 8 groups ( 7 mice in each group) according to the tumor volume and bioluminescent intensity to receive two cycles of treatments. The $1^{\text {st }}$ cycle consisted of doxorubicin (12 $\mu \mathrm{g} /$ mouse, intravenously (IV), every other day (QOD) for 4 times), sorafenib (200 $\mu \mathrm{g} /$ mouse, intragastrically (IG), every day (QD) for 7 times), or/and miR-34a (12 $\mu \mathrm{g}$ /mouse, IV, QOD for 4 times). The $2^{\text {nd }}$ cycle consisted of doxorubicin $(10 \mu \mathrm{g} /$ mouse, IV, QOD for 4 times), sorafenib (200 $\mu \mathrm{g} /$ mouse, IG, QOD for 4 times) or/and miR-34a (10 $\mu \mathrm{g} /$ mouse, IV, QOD for 4 times). At the end of the study, all mice were sacrificed and tumors were dissected and weighed. The lung tissues were dissected for ex vivo GFP imaging and fixed in $10 \%$ formalin, and then subjected to hematoxylin and eosin (H\&E) staining for histological evaluation in the Clinical Immunohistochemistry Laboratory at Roswell Park Cancer Institute (Buffalo, NY, USA). Additionally, serum was isolated using a serum separator (BD Biosciences, San Jose, CA, USA) and then subjected to blood chemistry profiling in the Comparative Pathology Laboratory at UC Davis. Serum cardiac troponin-I (cTnI) was analyzed with a Mouse Cardiac Troponin-I ELISA Kit (Life diagnostics, Inc. West Chester, PA, USA).

To establish artificial metastasis mouse models for survival study, 9-week-old female mice were inoculated with $5 \times 10^{6} 143 \mathrm{~B}-$ GFP-Luc cells in $250 \mu 1$ PBS per mouse via the tail vein injection. 12 days later, the mice were randomized to 4 groups to receive two cycles of miR34a, doxorubicin/sorafenib, doxorubicin/sorafenib + miR$34 \mathrm{a}$ or control vehicle treatment. The $1^{\text {st }}$ cycle consisted of doxorubicin (12 $\mu \mathrm{g} / \mathrm{mouse}$, IV, QOD for 6 times), sorafenib (200 $\mu \mathrm{g} /$ mouse, IG, QD for 10 times), or/and miR-34a (12 $\mu \mathrm{g}$ /mouse, IV, QOD for 6 times). The $2^{\text {nd }}$ cycle consisted of doxorubicin (10 $\mu \mathrm{g} / \mathrm{mouse}$, IV, QOD for 8 times), sorafenib ( $200 \mu \mathrm{g} /$ mouse, IG, QOD for 8 times) 
or/and miR-34a (10 $\mu \mathrm{g} / \mathrm{mouse}, \mathrm{IV}$, QOD for 8 times). Body weight loss over $10 \%$ was considered as death. All mice underwent complete necropsy for the confirmation of experimental pulmonary metastases. Survival was analyzed by Kaplan-Meier method and compared by Logrank (Mantel-Cox) Test (GraphPad Prism).

\section{Statistics analysis}

Statistical analysis was performed using GraphPad Prism. Depending upon the groups and variances, data were analyzed with one-way or two-way ANOVA. Additionally, Bonferroni post-tests were applied for multiple comparisons. Difference was considered as statistically significant at the level of $P<0.05$.

\section{ACKNOWLEDGMENTS}

The authors appreciate Dr. Yong Zhao for his technical support and helpful discussion.

\section{CONFLICTS OF INTERESTS}

The authors have applied for patent protection for the production and use of miR-34a prodrug reported in this paper.

\section{FUNDING}

This work was supported by NIH grants U01CA175315 and R01GM113888 (A.M.Y.), and P30CA093373 (R.D.W. and P.N.L.) as well as the Outstanding Medical Academic leader Program of Hubei Province and Huanghe Yingcai Program of Wuhan (A.X.Y.). C.J. was supported by the Chinese Scholarship Council (No. 201506270112).

\section{REFERENCES}

1. Chaffer CL, Weinberg RA. A perspective on cancer cell metastasis. Science. 2011; 331:1559-1564.

2. Christofori G. New signals from the invasive front. Nature. 2006; 441:444-450.

3. Steeg PS. Targeting metastasis. Nat Rev Cancer. 2016; $16: 201-218$

4. Gorlick R, Janeway K, Lessnick S, Randall RL, Marina N, Committee COGBT. Children's Oncology Group's 2013 blueprint for research: bone tumors. Pediatr Blood Cancer. 2013; 60:1009-1015.

5. Rivera-Valentin RK, Zhu L, Hughes DP. Bone Sarcomas in Pediatrics: Progress in Our Understanding of Tumor Biology and Implications for Therapy. Paediatr Drugs. 2015; 17:257-271.

6. Kager L, Zoubek A, Potschger U, Kastner U, Flege S,
Kempf-Bielack B, Branscheid D, Kotz R, Salzer-Kuntschik M, Winkelmann W, Jundt G, Kabisch H, Reichardt P, et al. Primary metastatic osteosarcoma: presentation and outcome of patients treated on neoadjuvant Cooperative Osteosarcoma Study Group protocols. J Clin Oncol. 2003; 21:2011-2018

7. Jaffe N. Osteosarcoma: review of the past, impact on the future. The American experience. Cancer Treat Res. 2009; 152:239-262.

8. Kansara M, Teng MW, Smyth MJ, Thomas DM. Translational biology of osteosarcoma. Nat Rev Cancer. 2014; 14:722-735.

9. Ta HT, Dass CR, Choong PF, Dunstan DE. Osteosarcoma treatment: state of the art. Cancer Metastasis Rev. 2009; 28:247-263.

10. PosthumaDeBoer J, Witlox MA, Kaspers GJ, van Royen BJ. Molecular alterations as target for therapy in metastatic osteosarcoma: a review of literature. Clin Exp Metastasis. 2011; 28:493-503.

11. Luetke A, Meyers PA, Lewis I, Juergens H. Osteosarcoma treatment - where do we stand? A state of the art review. Cancer Treat Rev. 2014; 40:523-532.

12. Webster RM. Combination therapies in oncology. Nat Rev Drug Discov. 2016; 15:81-82.

13. Chen QX, Wang WP, Zeng S, Urayama S, Yu AM. A general approach to high-yield biosynthesis of chimeric RNAs bearing various types of functional small RNAs for broad applications. Nucleic Acids Res. 2015; 43:38573869.

14. Wang WP, Ho PY, Chen QX, Addepalli B, Limbach PA, Li MM, Wu WJ, Jilek JL, Qiu JX, Zhang HJ, Li T, Wun T, White RD, et al. Bioengineering Novel Chimeric microRNA-34a for Prodrug Cancer Therapy: High-Yield Expression and Purification, and Structural and Functional Characterization. J Pharmacol Exp Ther. 2015; 354:131141.

15. Ho PY, Yu AM. Bioengineering of noncoding RNAs for research agents and therapeutics. Wiley Interdiscip Rev RNA. 2016; 7:186-197.

16. Zhao Y, Tu MJ, Wang WP, Qiu JX, Yu AX, Yu AM. Genetically engineered pre-microRNA-34a prodrug suppresses orthotopic osteosarcoma xenograft tumor growth via the induction of apoptosis and cell cycle arrest. Sci Rep. 2016; 6:26611.

17. Zhao Y, Tu MJ, Yu YF, Wang WP, Chen QX, Qiu JX, Yu $\mathrm{AX}, \mathrm{Yu}$ AM. Combination therapy with bioengineered miR34a prodrug and doxorubicin synergistically suppresses osteosarcoma growth. Biochem Pharmacol. 2015; 98:602613.

18. Nakatani F, Ferracin M, Manara MC, Ventura S, Del Monaco V, Ferrari S, Alberghini M, Grilli A, Knuutila S, Schaefer KL, Mattia G, Negrini M, Picci P, et al. miR-34a predicts survival of Ewing's sarcoma patients and directly influences cell chemo-sensitivity and malignancy. J Pathol. 
2012; 226:796-805.

19. Wang Y, Jia LS, Yuan W, Wu Z, Wang HB, Xu T, Sun JC, Cheng KF, Shi JG. Low miR-34a and miR-192 are associated with unfavorable prognosis in patients suffering from osteosarcoma. Am J Transl Res. 2015; 7:111-119.

20. Yan K, Gao J, Yang T, Ma Q, Qiu X, Fan Q, Ma B. MicroRNA-34a inhibits the proliferation and metastasis of osteosarcoma cells both in vitro and in vivo. PLoS One. 2012; 7:e33778.

21. Wu X, Zhong D, Gao Q, Zhai W, Ding Z, Wu J. MicroRNA-34a inhibits human osteosarcoma proliferation by downregulating ether a go-go 1 expression. Int J Med Sci. 2013; 10:676-682.

22. Duan Z, Yu AM. Bioengineered non-coding RNA agent (BERA) in action. Bioengineered. 2016; 7:411-417.

23. Mah LJ, El-Osta A, Karagiannis TC. gammaH2AX: a sensitive molecular marker of DNA damage and repair. Leukemia. 2010; 24:679-686.

24. Li Y, Guessous F, Zhang Y, Dipierro C, Kefas B, Johnson E, Marcinkiewicz L, Jiang J, Yang Y, Schmittgen TD, Lopes B, Schiff D, Purow B, et al. MicroRNA-34a inhibits glioblastoma growth by targeting multiple oncogenes. Cancer research. 2009; 69:7569-7576.

25. Li N, Fu H, Tie Y, Hu Z, Kong W, Wu Y, Zheng X. miR34a inhibits migration and invasion by down-regulation of c-Met expression in human hepatocellular carcinoma cells. Cancer Lett. 2009; 275:44-53.

26. Gaur S, Wen Y, Song JH, Parikh NU, Mangala LS, Blessing AM, Ivan C, Wu SY, Varkaris A, Shi Y, Lopez-Berestein G, Frigo DE, Sood AK, et al. Chitosan nanoparticlemediated delivery of miRNA-34a decreases prostate tumor growth in the bone and its expression induces noncanonical autophagy. Oncotarget. 2015; 6:29161-29177. doi: 10.18632/oncotarget.4971.

27. MacEwen EG, Kutzke J, Carew J, Pastor J, Schmidt JA, Tsan R, Thamm DH, Radinsky R. c-Met tyrosine kinase receptor expression and function in human and canine osteosarcoma cells. Clin Exp Metastasis. 2003; 20:421-430.

28. Oda Y, Naka T, Takeshita M, Iwamoto Y, Tsuneyoshi M. Comparison of histological changes and changes in $\mathrm{nm} 23$ and c-MET expression between primary and metastatic sites in osteosarcoma: a clinicopathologic and immunohistochemical study. Hum Pathol. 2000; 31:709716.

29. Subbiah V, Wagner MJ, McGuire MF, Sarwari NM, Devarajan E, Lewis VO, Westin S, Kato S, Brown RE, Anderson P. Personalized comprehensive molecular profiling of high risk osteosarcoma: Implications and limitations for precision medicine. Oncotarget. 2015; 6:40642-40654. doi: 10.18632/oncotarget.5841.

30. Liu L, Cao Y, Chen C, Zhang X, McNabola A, Wilkie D, Wilhelm S, Lynch M, Carter C. Sorafenib blocks the RAF/ MEK/ERK pathway, inhibits tumor angiogenesis, and induces tumor cell apoptosis in hepatocellular carcinoma model PLC/PRF/5. Cancer research. 2006; 66:1185111858 .

31. Wilhelm SM, Carter C, Tang L, Wilkie D, McNabola A, Rong H, Chen C, Zhang X, Vincent P, McHugh M, Cao Y, Shujath J, Gawlak S, et al. BAY 43-9006 exhibits broad spectrum oral antitumor activity and targets the RAF/MEK/ ERK pathway and receptor tyrosine kinases involved in tumor progression and angiogenesis. Cancer research. 2004; 64:7099-7109.

32. Pal HC, Baxter RD, Hunt KM, Agarwal J, Elmets CA, Athar M, Afaq F. Fisetin, a phytochemical, potentiates sorafenib-induced apoptosis and abrogates tumor growth in athymic nude mice implanted with BRAF-mutated melanoma cells. Oncotarget. 2015; 6:28296-28311. doi: 10.18632/oncotarget.5064.

33. Bertinchant JP, Polge A, Juan JM, Oliva-Lauraire MC, Giuliani I, Marty-Double C, Burdy JY, Fabbro-Peray P, Laprade M, Bali JP, Granier C, de la Coussaye JE, Dauzat M. Evaluation of cardiac troponin I and T levels as markers of myocardial damage in doxorubicininduced cardiomyopathy rats, and their relationship with echocardiographic and histological findings. Clin Chim Acta. 2003; 329:39-51.

34. Carlino MS, Long GV. Ipilimumab Combined with Nivolumab: A Standard of Care for the Treatment of Advanced Melanoma? Clin Cancer Res. 2016; 22:39923998.

35. Mohseny AB, Machado I, Cai Y, Schaefer KL, Serra M, Hogendoorn PC, Llombart-Bosch A, Cleton-Jansen AM. Functional characterization of osteosarcoma cell lines provides representative models to study the human disease. Lab Invest. 2011; 91:1195-1205.

36. Luu HH, Kang Q, Park JK, Si W, Luo Q, Jiang W, Yin H, Montag AG, Simon MA, Peabody TD, Haydon RC, Rinker-Schaeffer CW, He TC. An orthotopic model of human osteosarcoma growth and spontaneous pulmonary metastasis. Clin Exp Metastasis. 2005; 22:319-329.

37. Jung KA, Choi BH, Kwak MK. The c-MET/PI3K signaling is associated with cancer resistance to doxorubicin and photodynamic therapy by elevating BCRP/ABCG2 expression. Mol Pharmacol. 2015; 87:465-476.

38. Firtina Karagonlar Z, Koc D, Iscan E, Erdal E, Atabey N. Elevated hepatocyte growth factor expression as an autocrine c-Met activation mechanism in acquired resistance to sorafenib in hepatocellular carcinoma cells. Cancer Sci. 2016; 107:407-416.

39. Francia G, Cruz-Munoz W, Man S, Xu P, Kerbel RS. Mouse models of advanced spontaneous metastasis for experimental therapeutics. Nat Rev Cancer. 2011; 11:135141.

40. Abou-Alfa GK, Johnson P, Knox JJ, Capanu M, Davidenko I, Lacava J, Leung T, Gansukh B, Saltz LB. Doxorubicin plus sorafenib vs doxorubicin alone in patients with advanced hepatocellular carcinoma: a randomized trial. Jama. 2010; 304:2154-2160. 
41. Cortez MA, Ivan C, Valdecanas D, Wang X, Peltier HJ, Ye Y, Araujo L, Carbone DP, Shilo K, Giri DK, Kelnar K, Martin D, Komaki R, et al. PDL1 Regulation by p53 via miR-34. J Natl Cancer Inst. 2016; 108.

42. Wang X, Li J, Dong K, Lin F, Long M, Ouyang Y, Wei J, Chen X, Weng Y, He T, Zhang H. Tumor suppressor miR-34a targets PD-L1 and functions as a potential immunotherapeutic target in acute myeloid leukemia. Cell Signal. 2015; 27:443-452.

43. Li MM, Addepalli B, Tu MJ, Chen QX, Wang WP, Limbach PA, LaSalle JM, Zeng S, Huang M, Yu AM. Chimeric MicroRNA-1291 Biosynthesized Efficiently in Escherichia coli Is Effective to Reduce Target Gene Expression in Human Carcinoma Cells and Improve Chemosensitivity. Drug Metab Dispos. 2015; 43:1129-1136.
44. Chou TC. Drug combination studies and their synergy quantification using the Chou-Talalay method. Cancer research. 2010; 70:440-446.

45. Bi HC, Pan YZ, Qiu JX, Krausz KW, Li F, Johnson CH, Jiang CT, Gonzalez FJ, Yu AM. N-methylnicotinamide and nicotinamide $\mathrm{N}$-methyltransferase are associated with microRNA-1291-altered pancreatic carcinoma cell metabolome and suppressed tumorigenesis. Carcinogenesis. 2014; 35:2264-2272.

46. Su Y, Luo X, He BC, Wang Y, Chen L, Zuo GW, Liu B, Bi Y, Huang J, Zhu GH, He Y, Kang Q, Luo J, et al. Establishment and characterization of a new highly metastatic human osteosarcoma cell line. Clin Exp Metastasis. 2009; 26:599-610. 